\title{
Can States Be Turned into Automotive Innovation Hubs?
}

\begin{abstract}
The article considers the hypothesis that in the face of the overlap of four trends that will shape the future of the automotive industry: autonomy, urbanization, digitization, and electrification, achieving success in the automotive industry in the coming years will require synergistic cooperation between the private and public sectors. In the context of global competition encompassing not only individual enterprises but also entire ecosystems, countries will have to rethink their ability to provide added value to their economies. On the example of electromobility, the article proposes five success factors for its development depending on the state situation. These are: the strength of traditional car companies, social expectations, job creation potential, internationalization possibilities, and the ability to incubate new entities. From the initial analysis, which requires further development and verification, it appears that countries such as China at the start seem to be in a privileged position to make the most of the potential of new mobility.
\end{abstract}

Keywords: Electromobility; Urbanization; Autonomization; Cybersecurity; Role of the State.

\section{Introduction}

The central goal of the New Structural Economics is to rethink the state as driving force for development. The liberal paradigm that has been functioning in the West since the mid-twentieth Century, part of which is world trade, gradually adopted by developing countries and then strengthened by the fall of communism, has led to increased standards of living on the whole planet. Taking into account GDP per capita, the statistical inhabitant of the planet has gained as much as four times between 1980 and the present moment, and the proportion of the poorest fell from $42 \%$ in 1993 to even less than $10 \%$ currently (Roser, 2018).

However, very serious global inequalities have turned out to be a side effect of the global market. Deepened by the financial crisis of 2007-2008 and the eurozone crisis since 2009, the growing gap between a handful of the richest and all the others has put into question the legitimacy of globalization. Enormous 
inequalities have become a source of contestation on the part of economists (Piketty, 2010). They also translated into the growing demand of voters for identity politics (Fukuyama, 2018).

As a result, the states are re-entering the arena. Although it would be more accurate to say they never really left it, especially the most effective and developing ones. But a recurring reflection on the need for industrial policy, long-unseen customs wars, and even more frequent use of sanctions policy, are a novelty in the world of developed countries. After years of consuming the fruits of growth through social policy, taking a recipe for growth from the Washington Consensus, strengthening regional ties and building global rules, all countries have been forced to rethink their role. In particular, how to become an added value for their economies.

The hypothesis adopted in this article is that states cannot do this effectively in abstract from the global trends that shape technology, business, society, and our surroundings. One of the most interesting fields of accumulation of these trends and the upcoming confrontation will be the automotive industry, in which four forces are going to play the pivotal role: autonomy, urbanization, digitization, and electrification. Neither a company nor the state can bring out the full potential of their interaction by themselves. Thanks to the fact that the synergic cooperation of the state and companies will remain an exception rather than a rule, the prize for its achievement will be global leadership and economic pension in one of the world's most lucrative branches of the economy.

\section{Autonomous Transport}

The beginning of the twenty-first Century is a period of unprecedented acceleration of innovation. Describing this situation, a number of authors expect the appearance of a "technological point of singularity" (Kurzweil, 2005), in which the machine's intelligence overtakes man's capabilities and, consequently, a gradual merger of man and machine (Harari, 2018).

For the automotive industry, however, this moment is not associated with a merger, and indeed with something exactly opposite. People will not have to drive their cars because the machine will be smart enough to do the job for them. Being the result of digital technology and the artificial intelligence and automation that arose from it, autonomous transport stimulates the imagination and mobilizes leading research teams and resources. Most large car manufacturers anticipate a breakthrough in the first half of 2020s and the 
appearance of the first fully autonomous vehicles on the roads. At first, they will be luxury vehicles or delivery vehicles moving on predictable and long routes - long-haul transport. Hardly anyone, however, doubts that in the perspective of 2030 autonomous vehicles in some form will also appear in cities.

Technological challenges are no longer an area reserved only for technology companies. Alliances are formed between traditional automotive players and new technological players, such as BMW and Intel, Fiat-Chrysler and Google (Waymo), or Renault-Nissan and Google. According to Morgan Stanley, between 2013 and 2016 the technology companies' purchases increased by tenfold by non-technological companies (Morgan Stanley, 2018). As buyers and hubs of digital innovation, companies such as Ford, GM, or Uber joined the traditional technology giants like Apple, Google, Facebook, and IBM. Among various areas of technology, artificial intelligence has become the fastest growing segment of growth. One of its main applications - recognition of the environment necessary for the widespread of autonomous cars, that is machine vision - has brought one-third of the M\&A transactions in this area in the last 24 months. The most spectacular was the purchase by the American Intel in 2017 of the Israeli start-up Mobileye producing a visualization system to assist the driver in driving. Recently, the takeover of the American start-up xPerceptions by Chinese technology giant Baidu was symptomatic. It proved that the race to an autonomous car ceased to be the exclusive domain of the traditional Western world (Hampleton, 2018).

It can be expected that in perspective of the next dozen or so years, the first fully autonomous vehicles will appear and gradually start gaining popularity in an increasingly complex communication environment - finally in cities as well. An autonomous revolution will relieve people from driving, giving them more time for other activities. But at the same time, it will encourage longer journeys, and thus further increase the distance between home and workplace. Provided that the development of infrastructure with the new vehicle capabilities is kept up, this will translate into further, spectacular development of cities.

\section{Urbanization}

While at the beginning of the nineteenth Century only one in 50 world residents lived in the city, nowadays, up to half of the world's population inhabit urban areas. The largest cities in the world have experienced spectacular growth over the last couple of decades. In 1990 there were 10 megacities counting over 
10 million inhabitants each. By now their number increased to almost 30 and they are inhabited by little less than 500 million people. In perspective of 2050 , two out of three people will live in cities around the world. This means between 6 and 7 billion people out of 9 billion living on the entire planet (...).

Urbanization entails a number of consequences, the scale and intensity of which we cannot quite imagine. One of the most important will be the answer to the mobility needs: from cities "into the world" - as tourists; between the place of work and place of residence - as employees; between cities - on business. There will be a growing need for individualization of moving, although not necessarily ownership of transportation means. Convenience measured by access and ease of use, rather than the social aspiration measured by possession, will be the new norm. Already today, New York has much lower saturation with cars than Warsaw. The car as a tool for self-realization will lose its importance to the benefit of a vehicle allowing for smooth transition from place A to place B. The success of Uber or Lyft is already a foretaste. Car companies are more and more aware of this, and the global alliances built by city carriers and vehicle manufacturers are meaningful in this context: GM and Lyft, Volvo and Uber.

Vehicle banalization is inevitable if we realize the scale of the upcoming challenge. The supply of means of transport, especially cars, is very uneven between different parts of the world. There are between 300 and 600 cars in Europe per 1000 inhabitants. In the United States, this is almost a one-to-one ratio. In India, this ratio still amounts to only 50 cars per 1000 inhabitants. At the same time, it must be remembered that India is a rapidly growing country, a country of young people: in 2030, $60 \%$ of Indians will be under thirty; in 2050, 700 million people will live there in cities. Can we imagine even more cars moving on the roads of this country? Judging by the crowded streets of New Delhi, Calcutta, Mumbai and other major cities, it seems next to impossible. Satisfying the needs and aspirations of city dwellers, e.g. in India or China, in the field of mobility will become one of the greatest challenges of the $21^{\text {st }}$ Century.

In the context of urbanization, it is not clear whether the proliferation of autonomous vehicles will contribute to the discharge of communication problems or, on the contrary, will lead to their deepening. On the one hand, through sharing, an autonomous vehicle will free today's unused vehicle time, while also freeing parking spaces. On the other hand - man will be able to manage his time in a different way, allocating it to entertainment, work and rest. The convenience of not owning a means of transport combined with cheapness of using it may cause displacement of public transport, which is already partially observed in cities, where it has become popular, e.g. Uber. 
As a result, there is a risk that the city will spread even more in space and its center will become even more congested. Initial research based on experiments with autonomous transport in Boston seems to confirm this thesis (BCG, 2018). As a result of the hypothetical popularization of autonomous transport, the total travel time will be shorter. However, in the city center it will become longer ("congestion effect"), while in suburbs it will significantly shorten commuting (consequently provoking the "stretch effect"). However, these tests are conducted with ceteris paribus, without changing other parameters, such as public transport policy, taxation and restriction of entry to city centers, availability of parking spaces. Then, as revealed by the example of Tokyo, it is possible to radically relieve the city center of car traffic, thanks to very good access to public transport. On similar premises the authorities of Singapore rely, as they assume that by $2030,80 \%$ of the city's residents will have a subway or bus station within a 5-minute walk from where they live. The best-configured city systems will discourage individual vehicles.

In any case, the interaction between urbanization and autonomy will be a challenge. Through autonomy, the cost of individual transport will be reduced, which will inevitably translate into increased demand for such services. As a result, the role of the brake will be taken by the city authorities and regulators. By restricting traffic, supporting public transport, expanding the infrastructure will be limited by individual vehicles in the centers. Their ally will be the digital integration of vehicles and infrastructure.

\section{Vehicles Digitally Integrated}

One of the most obvious megatrends of recent years, which is already talked about a lot, is the increasing significance of communication and data exchange between devices. In particular, vehicles integrate digitally with other vehicles and infrastructure. In 2020, all new vehicles will be connected in the network (BCG, 2018). It is an opportunity to increase traffic safety, reduce failure. Autonomous vehicles connected in the network will limit the role of the weakest link in driving a vehicle, which is a human being. They will be less vulnerable to accidents. Communication with service facilities will allow faster and better response to failures and technical problems. But not only that.

Digital and communication integrated vehicles will open new perspectives for insurers, advertisers, and various service providers. Relieved from the attention needed to drive a vehicle today, the passenger will become an attractive object 
of advertising activities. The ability to deliver products to moving vehicles will enable the integration of drones and vehicles. New business models and new industries will appear around mobility.

Gradual digitization of all areas of human activity opens up enormous potential. In the context of autonomous vehicles and combined infrastructure, it also challenges the security of data. The future incidents will probably be less numerous, but the ones that will take place may be more spectacular if they are caused by terrorist activity or system failure. Cyber security will become one of the most crucial areas of the economy. The need to provide it will also motivate the growing intervention of states. It will not be possible to maintain the overall system continuity without centralized monitoring. While the creation of security standards will be the private sector's work, their popularization will be the role of the regulator.

Digitization will go hand in hand with the growing importance of electricity. While it is said that the $20^{\text {th }}$ Century was under the sign of crude oil, more and more points to the fact that the $21^{\text {st }}$ will be the Century of electrification. Electricity as a drive for the development of civilization is also a new perspective for the road transport sector.

\section{Electrification as a Response to Environmental Pollution and Climate Challenges}

The rapid economic development of the end of the $20^{\text {th }}$ Century is also a growing climate and environmental challenge. From perspective of the commitments undertaken by the States under the Paris Agreement, it has become necessary to reduce carbon dioxide emissions in transport. It has become the fastest growing source of emissions in OECD countries (IEA, 2018). In the rapidly developing countries of the South, cities have become the area of smog and the main source of noise. Across the world, air quality is deteriorating at an unprecedented rate due to growing vehicle traffic. It involves the emission of soot particles and nitrogen oxides. Over three million premature deaths in the world are associated with air pollution with $2.5 \mathrm{PM}$ soot particles. One in four of these molecules comes from transport (CCAC, 2018).

Electric cars are the answer to the growing demand for cleaner and quieter cities. Replacing a combustion engine driven car with an electric car reduces emissions of nitrogen oxides by up to $80 \%$. Electric cars allow to alleviate the smog in cities. They also allow to reduce carbon dioxide emissions by between 
$25 \%$ and even $60 \%$, depending on the method of electricity production. The popularization of electric cars in cities will reduce noise levels on the streets. In addition, an electric car can be very convenient. As research shows in markets where they have become widespread - e.g. in Norway or in California - drivers are happy to charge their car at home without having to stop at service stations (IEA, 2018) In many countries, charging at night also lowers the costs of using the car. There is no manual transmission, which is especially convenient when driving in the city.

Until recently, until the first years of the $21^{\text {st }}$ Century, electric vehicles had no chance of becoming widespread. The prohibitive cost of batteries, the lack of charging infrastructure, the reluctance of traditional car manufacturers to cannibalize their know-how, the lack of a secondary market have acted as serious barriers in this respect. However, several factors indicate that they will soon become cost-competitive compared to traditional combustion-engined vehicles. Among the alternative fuels, electromobility will the soonest become popular. It will leave hydrogen vehicles behind, as well as ones fueled by biofuels and natural gas, although of course it cannot be ruled out that the next innovations will break this trend with time as well.

This will happen because the cost of owning a car is not only the cost of purchase, but also that of fuel, maintenance and repairs. Driving around in electric cars has already become cheaper and more convenient than with combustion cars. Maintenance and service costs are lower, because electric cars are less complex (their motor and transmission have about 1000 parts less), they do not need oil change or filters. However, the key to their popularization will be the falling cost of lithium-ion batteries, which will translate into a lower price for buying an electric car. The batteries, constituting $40 \%$ of its production costs, are cheaper by $10-15 \%$ annually (IEA, 2018). As a result, it is estimated that in the 2020-2022 perspective, the total cost of owning an electric car - calculated in its entirety, including costs of purchase and use over a period of at least five years - will become lower than that of combustion engine driven cars. The market will grow faster and faster, going from linear to exponential growth. This is already visible: it took 60 months to sell the first million electric cars, the second million took only 17 months, the third one was already down to 10 months, and the fourth million was achieved in August 2018 in 6 months. In the global perspective, it is estimated that from the current $1 \%$ of vehicles, the "electrics" will achieve between 20 and $40 \%$ market share. In Europe alone in 2030, it will be 5 million new electric cars per year. In the 2040 perspective, between 250 and 500 million vehicles will be powered by electricity among 2 billion around the world. 


\section{The Development of the Automotive Industry and the Role of the State}

Means of transport, especially the individual car, will therefore undergo intense (r)evolution over the next decades. Increasing urbanization combined with digitization and autonomy will force new business and regulatory models. The car will be driven from the realm of ownership to the sphere of use. Technological progress will allow the evolution of the drive from internal combustion engine to electric motor.

We will use the vehicles of the future in other ways than ever before, evolving from ownership to sharing. It is estimated that in 2025 there will be 80 million car-sharing users in the world. In perspective of 2030, one third of travel in India will be made using shared means of transport, which will put this country in the leading role of this type of communication. Sharing will take root as an alternative to the development of public transport, which among developing countries does not have the popularity it is due, requiring long-term spatial planning and funds for investments.

Electric vehicles of the future, charged at night, will move in an automated manner on predefined routes. Diversified delivery vehicles will spread from heavy trucks through semi-heavy trucks to last mile transport, possibly including drones. While the first cars looked like cabs, the vehicle of the future does not have to resemble its late $19^{\text {th }}$ Century grandfather or father from the $20^{\text {th }}$ Century. Between the family vehicle and the bus, there will be space for small, autonomous vehicles transporting for short distances: between the place of residence and the subway; within the district. This is an opportunity for new companies that will focus only on electric cars. In particular, the creation of a low-budget electric car will radically change the market image.

Electric cars will reduce the dependence on oil. Many states will find this argument attractive enough to support the widespread use of electric vehicles.

The state will play a key role in accessing the new value potential. There will be no autonomous transport without sophisticated legal regulations, defining parties' responsibility and security standards. Sharing transport will significantly benefit from privileges, including fiscal ones. Electrification will not be possible without proper determination of legislators and initial co-financing from public funds. Digital mobility will be conditioned by access to sophisticated cybersecurity competences that only the community at the state level will be able to collect as a public good. There will be no new, high-paying jobs without advanced education systems. 
New business models will open, the old ones will be ruined, giving new players the chance or strengthening the advantage of the existing ones. New mobility, digital, autonomous, electric, and shared is the prospect for the automotive industry to grow. USD 2,500 billion in new revenue over the next 20 years is estimated. At the same time, the existing technologies will practically not budge. The entire $40 \%$ sector growth will be attributed to new mobility, opening the "blue ocean" (...) for pioneers. In a traditional car business, the lack of growth dynamics will mean regression (BCG, 2018). More simple competition, inevitably costly, a continuation rather than a breakthrough will cement the "red ocean" as a competitive space for the traditional car industry.

The best pioneers will collect priority pension. Countries that synergistically transform their industry towards new mobility will gain a chance for global leadership. Companies that benefit from the imagination of their managers and legislators will take advantage of the potential of domestic markets and assets to build global advantage. New mobility re-evaluates the current competitive landscape. Although traditional car manufacturers will remain well positioned to capture the potential of the new value, they certainly should not take it for granted. The electrification of the vehicle will put everyone on the new starting grid. New business models will open up new spaces of competition. New producers, such as Tesla, NIO, Faraday Future and Lucid among others, have a unique chance in this new race for an equal start together with BMW, Renault and Ford. It may also turn out that electro-mobile innovators - thanks to the unique chance of the lack of accumulated luggage of the traditional manufacturers' legacy - will gain an advantage in the new global deal, even at the start. After all, the Tesla valuation that surpasses the capitalization of GM really proves something.

\section{Opportunities for New Producers}

The combination of business, social, and technological change is a unique moment for new producers. The domination of the internal combustion engine has established a specific market structure prevailing throughout the $20^{\text {th }}$ Century. However, classical producers have no interest in the rapid electrification of transport. On the one hand, they need time to recoup their investments in combustion cars. Then, we have to remember they will lose up to $50 \%$ of the margin currently generated by the service. It is through selling and fitting spare parts that they get their profitability throughout the entire life 
cycle of the vehicle. Considering that an electric vehicle is significantly simpler, they will not be able to use their production assets or suppliers.

It is estimated that for the Volkswagen group alone, the loss of jobs caused by electrification of vehicles amounts to reduction of employment by at least $10 \%$, or 60,000 employees. By defending themselves, classical producers apply all available, even illegal, methods to limit the pace of this transformation, which can be seen by the collusion proceedings launched in September 2018 by the European Commission to limit the popularization of clean transport by European producers. They conduct electrification in a selective manner, focusing on non-mass segments. To a lesser extent they are trying to dominate new areas, but all in all they are mostly fighting to maintain their existing ones.

An additional challenge is the baggage of inefficiency that they, historically, carry behind them. Their extensive dealer networks are ineffective and costly in the internet age, as illustrated by the direct selling method used by Tesla. The employment structure in factories is not adapted to electric cars due not only to scale, but also to competences. Skills in the field of energy chemistry, electrical engineering, computer science necessary for the production of battery "computers on wheels" replace the classical skills in the field of "hot" mechanics.

New mobility will allow the creation of high-paying jobs. Each new factory of electric cars or complex components means hundreds, and often thousands, new jobs. Every workplace at the car manufacturer allows creating additional 3-5 jobs outside the factory, e.g. from sub-suppliers. Not only high salaries, but also competences in the field of automation, artificial intelligence or cyber security will bring additional benefits in other areas: smart city, energy, security, IT banking, insurance. New mobility companies will contribute to the promotion of their country's image.

Launching profitable production at the level of several hundred thousand copies is an investment of several to several billion dollars, which, however risky, may already be attractive for the investors, and certainly for the countries and regions that will bet on them. A telling example of this is the creation of Tesla supported by public funds, but also the tremendous capitalization, which is now followed by subsequent ones.

\section{Electrification of Transport and Strategies of Selected Countries}

However, not all countries and not every economic ecosystem will be able to benefit from the described (r)evolution. Most countries will become stuck in 
inefficiencies characterized by bureaucracy or in the sluggishness of the political system. There are few places in the world where it is possible to accumulate sufficient capital to incubate new, risky businesses. In many mature markets, the technological change will encounter the resistance of the contemporary "Luddites", for whom it will carry the loss of previous occupation. Even if new entities germinate locally, and the regulatory system proves efficient enough to support them, in the economically fragmented world which beacons on the horizon it is not sure at all whether they will be able to lead them to global markets, giving the chance to spread their wings. Obstacles will abound and hinder or stop the launch of synergic cooperation between the state and companies in its area of influence.

The inclusion of all possible interdependencies between these four trends and strategies of states is a calling that goes beyond a single article. However, to build a certain set of hypotheses - success factors of synergic cooperation - the described fourfold revolution has been reduced only to the technological change, i.e. the transition from a combustion vehicle to an electric motor.

To achieve the full development potential resulting from electrification of vehicle drives, it is assumed that effective interaction between the public and private sectors will be based upon a combination of at least five factors: the strength of traditional car companies, responses to social expectations, potential for new jobs, internationalization opportunities, and the ability to incubate new players. Each of them is outlined below on the example of seven countries: Germany, China, USA, France, Great Britain, Norway, and Poland. The choice of countries is arbitrary, and the description of the situation in each of them does not aspire to be seen as exhaustive, but only serves to set some hypotheses that will be the basis for further research.

The biggest challenge on the road to using the potential of electric mobility is the strength of traditional car companies. Because effective technological change requires smooth and synergic cooperation between the state and the private sector, countries in which the traditional automotive industry operates will be subject to tendencies to slow it down. In particular, the strong surplus of EUR 150 billion in export in the automotive industry, achieved due to accumulated know-how in the field of internal combustion engine, Germany will treat electrification of transport in more defensive rather than offensive categories. On the other hand, China will see an opportunity to "jump over, not catching up", i.e. to create its own industry in a new technological niche in opposition to today's tycoons. Countries like Poland, Norway, or the United Kingdom - deprived of domestic producers - will be able to incubate new entities in the technological change. The positions of the US and France, positioning 
themselves on the opposite poles in terms of climate ambitions, will to some extent be the tributaries of these elections.

The development of electromobility will proceed best where it will respond to social expectations. Countries where societies struggle with air pollution, such as China or Poland, will not have difficulty in convincing their societies to the benefits of clean transport. Also, the population density of megacity, such as Paris, will help build support for it. Environmental and climate awareness will contribute to it becoming widespread, at least in some US states (e.g. California), in Germany, and Norway. An obstacle will be the financial possibilities of societies, toning the development of expensive electric vehicles in poorer societies such as China and Poland, and promoting them in the rich ones, such as Norway or California.

The potential for creating new jobs will be greatest in dynamically developing countries, especially in industrial terms, in countries such as Poland and China. For Germany and France, the employment balance will initially be negative, causing resistance from trade unions confronted with the loss of traditional jobs. Norway or Great Britain will face a difficult situation, the former due to the small scale of the car industry, the latter due to Brexit, which entails considerable uncertainty for companies operating on the islands. However, this last argument can also strengthen the government's determination to seek all possible ways to create new employment. Given the importance and diversity of the American market, the global technological revolution will support jobs there, even if the balance across individual states will be diametrically different.

For all the countries discussed, the possibilities of internationalization, understood as an ability to establish productive international cooperation, as well as building the image of a country that positively resonates with electrification of transport, are very important. Pioneers such as Norway and the largest market - China - will benefit the most. Inconsistency in climate policy between the federal government and certain states, in particular California, will make the possibility of using electromobility for promoting the United States rather ambiguous.

There is still the ability to incubate new players, which is one of the most difficult conditions to meet, and at the same time a prerequisite for success. In the best situation are mature economies with strong competences, advanced cooperative ties, and having high-risk capital resources, in particular the US. The countries that have adopted radically different models of development, such as China, having a strong tradition of state control and, at the same time, tools for its expression in the sphere of the economy, have an advantage here. In the most difficult situation are the countries of the European Union 
bound by common rules of competition protection. France, confronted with the challenges of deindustrialization for years, has no tools for incubating industrial entities. The German economy is also relatively traditional, although it manages to build new entities, also in the field of electromobility, even for the needs of German mail. Being at the middle stage of Brexit, the United Kingdom will not have the full capacity to use all the opportunities that its economic potential and access to financing offers. Positions of Poland and Norway are also weak.

The above considerations have been included in tabular form, where they were assigned grades from the least favorable (-), through neutral (0) to good $(+)$ and very good $(++)$.

Table 1. Schematic evaluation of the prospects for the development of electromobility for selected countries

\begin{tabular}{|l|c|c|c|c|c|c|}
\hline & $\begin{array}{c}\text { Lack of natural } \\
\text { opponents } \\
\text { hampering } \\
\text { the development } \\
\text { of electromobility }\end{array}$ & $\begin{array}{c}\text { A response } \\
\text { to challenges } \\
\text { and social } \\
\text { opportunities }\end{array}$ & $\begin{array}{c}\text { The } \\
\text { possibility } \\
\text { of creating } \\
\text { new jobs }\end{array}$ & $\begin{array}{c}\text { Potential } \\
\text { in the } \\
\text { international } \\
\text { sphere }\end{array}$ & $\begin{array}{c}\text { The ability } \\
\text { to incubate } \\
\text { new players }\end{array}$ & Total \\
\hline Poland & + & + & ++ & + & - & 4 \\
\hline China & ++ & + & ++ & ++ & ++ & 8 \\
\hline Norway & + & ++ & 0 & ++ & - & 4 \\
\hline Germany & - & + & - & + & + & 1 \\
\hline USA & 0 & + & + & + & + & 4 \\
\hline France & 0 & + & + & + & + & 1 \\
\hline $\begin{array}{l}\text { Great } \\
\text { Britain }\end{array}$ & + & + & + & + & 2 \\
\hline
\end{tabular}

The scale from the worst to the best rating: $-, 0,+,++$

Source: own study.

As a result, a hierarchy of countries emerges that have the best conditions for the popularization of electromobility. China seems best positioned to take advantage of the electromobility revolution. The size of its market, the ability to support pioneers, benefits of the global technological revolution predestine this country to take on global leadership in the field of electrification of transport. The facts that every second electric vehicle in the world is sold in China, that the largest lithium-ion cell factories are built there and that enterprises such as BYD, albeit from a great geographical distance, dominate the world market of electric buses, confirm this diagnosis. USA, Norway and Poland figure high in the ranking, for various reasons: USA as a global technology leader and the most innovative economy in the world. Norway, for its considerable wealth 
and expectations of its residents. Poland - because it successfully aspires to the group of the $21^{\text {st }}$ Century industrial tigers. The Great Britain ranks in the middle, while Germany and France seem to face the least favorable situation, where electromobility means confrontation with traditional industry in the context of a very uncertain fight to maintain global supremacy.

\section{Conclusion}

It should be emphasized that the above comparison is illustrative and schematic. It requires empirical verification. Its value is in the fact that it indicates factors that may affect the success of a given country and its companies, called synergic cooperation. On the example of electromobility alone, it shows various motivations and various barriers that may be experienced by countries on their way to reaching the potential value that are going to emerge from the overlap of the four trends that will shape the car industry of modernity: autonomy, urbanization, digitization, and electrification.

There are many indications that it is the synergistic cooperation between the state and the private sector that will be a prerequisite for taking advantage of the opportunities that are emerging in the field of new mobility. In most countries of the world these opportunities will remain undeveloped, but wherever you can reach for them, the prize will be a competitive industry, high-paying jobs and a global rent resulting from technological advantage.

\section{References}

BCG. (2018). Analiza rynku elektromobilności i jego potencjatu. Warszawa: The Boston Consulting Group.

CCAC. (2018). Briefing Paper by Climate and Clean Air Coalition for G7 Environment Ministers' Meeting on Urgent Action and Reduction Opportunities. Halifax, Canada: Climate and Clean Air Coalition.

Fukuyama, F. (2018). Against identity politics. Acquired from: https://www.foreignaffairs.com/ articles/americas/2018-08-14/against-identity-politics.

Hampleton Partners. (2018). Artificial Intelligence AI market report. Acquired from: https:// hampletonpartners.com/mediaarticle/hampleton-partners-artificial-intelligence-ai-marketreport/.

Harrari, Y. (2018). Homo Deus. Warszawa: Wydawnictwo Literackie.

IEA. (2018). Global EV Outlook. Paris: International Energy Agency. 
Kurzweil, R. (2013). Nadchodzi osobliwość. Warszawa: Kurhaus Publishing.

Morgan Stanley. (2018). 5 acquisition trends investors should watch in 2018. Acquired from: https://www.morganstanley.com/ideas/5-acquisition-trends-investors-should-watchin-2018.

Piketty, Th. (2013). Le Capital au XXIe siècle. Paris: Edition de Seuil.

Roser, M. (2018). The short history of global living conditions and why it matters that we know it. Acquired from: www.ourworldindata.org.

UNGC (2016). Zrównoważone miasta. Życie w zdrowej atmosferze. Warszawa: United Nations Global Compact. Acquired from: http://ungc.org.pl/programy/zrownowazone-miasta/Miasta zrównoważone. 